\title{
Antihistamine Activity of Steam-exploded Oak Extract Containing Phenolic Compounds
}

\author{
Ji Young Jung, ${ }^{a}$ Si Young Ha, ${ }^{\mathrm{b}}$ Tae-Heung Kim, ${ }^{\mathrm{b}}$ and Jae-Kyung Yang ${ }^{\mathrm{a}, *}$
}

\begin{abstract}
The aim of this study was to investigate the antihistamine activity of steamexploded oak (Quercus variabilis) extract containing phenolic compounds. The antioxidant activity increased with residence time of the steam explosion process. The $50 \% \mathrm{EtOH}$ extract had total phenolic compound content of $82.2 \%$ and $46.2 \mathrm{mg} \mathrm{GAE} / \mathrm{g}$ extract and vanillic acid, ferulic acid, and vanillin were identified. Treatment with $50 \% \mathrm{EtOH}$ extract decreased the diameters of histamine-induced wheal and erythema responses in human volunteers. In patients with atopic dermatitis, topical administration of $50 \% \mathrm{EtOH}$ extract led to significant diseases and improvement in terms of sleep disturbance, pruritus, xerosis, desire to scratch, and erythema. This study suggested that steam-exploded oak is rich in phenolic compounds with high antioxidant and antihistamine activities, and the extract may be a promising source of new antihistamine agents and pharmaceuticals.
\end{abstract}

Keywords: Oak; steam explosion; Phenolic compound; Antioxidant activity; Antihistamine activity

Contact information: a: Division of Environmental Forest Science/Institute of Agriculture and Life Science, Gyeongsang National University, Jinju, 52828, Republic of Korea; b: White-Line Skin Clinic, Changwon, 51496, Republic of Korea; *Corresponding author: jkyang@gnu.ac.kr

\section{INTRODUCTION}

Oak is a tree species of the genus Quercus commonly found in regions with temperate climate. Oak extract has been used to treat various inflammatory skin diseases because of its astringent, anti-inflammatory, and antipruritic effects. In traditional Asian medicine, oak bark is used to cure diarrhea, relieve pain, and treat skin diseases such as cellulitis, athlete's foot, and atopic dermatitis (Reuter et al. 2010; Lee et al. 2011). According to Lee et al. (2011) the Q. variabilis Blume extract reportedly exhibited an antiinflammatory effect on dinitrochlorobenzene-induced contact dermatitis. Muliawan et al. (2006) reported that the methanolic extract of $Q$. lusitanica seeds inhibits the replication of dengue virus type 2 (DEN-2) in vitro. Nur Syukriah et al. (2014) confirmed that $Q$. infectoria is a rich source of both gallic acid and tannic acid, which might be responsible for its antioxidant and antibacterial activities. Furthermore, studies showed that aqueous extract exhibited the highest antioxidant activity (approximately 94.6\%) and acetone extract yielded the largest inhibition zone in a disc diffusion assay $(19.0 \mathrm{~mm})$. Findings published by Moriyama et al. (2007) suggest that a reduction in oxalate-induced $\mathrm{O}_{2}$ production contributes to the cytoprotective effects of the extract of $Q$. salicina/ $Q$. stenophylla Makino. Although $Q$. variabilis extract has long been used to treat skin diseases, empirical evidence pertaining to its effects is scarce. Particularly, there is no study on the effect of $Q$. variabilis extract on dermal disorders, except in the case of dermal disease of endophytic fungus or Ganoderma lucidum (Wang et al. 2006) in Q. variabilis. 
Atopic dermatitis is a chronically relapsing inflammatory skin disease commonly associated with inhalant allergies (Hon et al. 2004) and a chronic inflammatory skin disease characterized by sleep disturbances, pruritus, xerosis, skin scratching, and erythema in response to environmental triggers (Choi et al. 2014). There is no definitive cure for atopic dermatitis, and the current effective treatment involves topical application of immunosuppressive steroids with undesirable side effects. Therefore, there has been a rising interest in the development of safer and non-steroid formulas for the treatment of atopic dermatitis. Atopic dermatitis has been associated with oxidant stress and diminished antioxidant defenses (Kirby and Schmidt 1997; Briganti and Picardo 2003). Pathologically and therapeutically, Briganti and Picardo (Briganti and Picardo 2003) reported strong correlations between antioxidant imbalances, oxidative lipid breakage, and skin diseases (including atopy). Therefore, oxidative stress levels must be reduced in atopic patients. Many researchers have confirmed that phenolic compounds enhance in vitro development of atopic dermatitis-like skin inflammation (Kojima et al. 2000; Al-Waili 2003; Lee et al. 2014; Działo et al. 2016; Taofiq et al. 2016; Tsang et al. 2016).

The effective extraction and separation method of phenolic compounds from plants is not yet well established. Steam explosion has also proved to be an effective method for releasing phenolic compounds bound to polysaccharides in the cell wall (Garrote et al. 2004; Kurosumi et al. 2007; Castro et al. 2008; Gong et al. 2012; Sun et al. 2014). The principle of the steam explosion treatment is the steam hydrolysis at high temperature and pressure, followed by sudden reduction of the pressure for physical treatment of the hydrolyzed product to produce low-molecular weight substances (Kurosumi et al. 2007).

In this study, the phenolic compounds obtained from the steam explosion of oak was characterized and quantified, and antioxidant activity and antihistamine activity were evaluated. In addition, effects of atopic dermatitis symptom mitigation was tested in atopic dermatitis patients.

\section{EXPERIMENTAL}

\section{Materials}

Oak (Q. variabilis) was collected from the forest around the city of Hongcheon in South Korea and chipped to a particle size of approximately $2 \times 2 \times 0.5 \mathrm{~cm}^{3}$ for steam explosion.

\section{Preparation of extract}

The oak chip was submitted to steam-explosion as a pretreatment in a custom-built batch pilot unit (Jung et al. 2015). The reactor was steam-exploded to the desired pressure $25 \mathrm{~kg} / \mathrm{cm}^{2}$ with saturated steam for 5 to $30 \mathrm{~min}$. The steam-exploded oak chip material was collected in a cyclone, and after cooling to about $40{ }^{\circ} \mathrm{C}$, air-dried and hammer-milled to a particle size of $-20 \mathrm{mesh} /+80$ mesh.

Water extraction was carried out with distilled water (solid:water ratio, 1:20 [w/v]) using autoclave at $121{ }^{\circ} \mathrm{C}$ for $30 \mathrm{~min}$. The extract was centrifuged at 3,000 rpm for $30 \mathrm{~min}$ before supernatants were filtered through a Whatman No. 2 filter paper. Ethanol extraction was performed from steam-exploded oak chip material using different ethanol concentrations ranging from $25 \%(\mathrm{v} / \mathrm{v})$ to $95 \%(\mathrm{v} / \mathrm{v})$ for $24 \mathrm{~h}$ at room temperature (solid: solution ratio, 1:20 (w/v)). The water extract (aqueous) and ethanol extract $(25 \% \mathrm{EtOH}$, 
$50 \% \mathrm{EtOH}, 75 \% \mathrm{EtOH}$, and $95 \% \mathrm{EtOH}$ ) were dried in a freeze dryer to make the powder, and then used to antioxidant activity, total phenolic compound, phenolic compound, and antihistamine activity (Fig. 1).

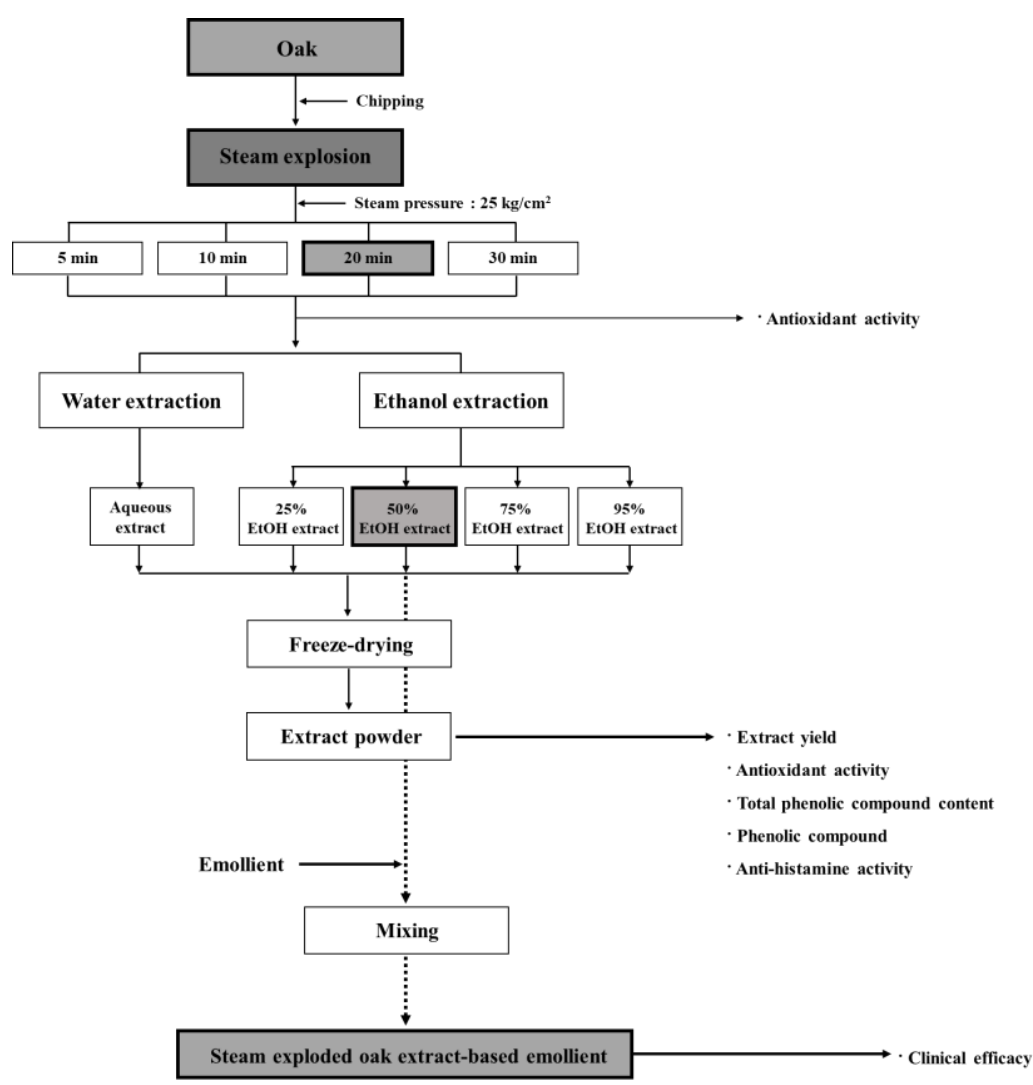

Fig. 1. Scheme of experimental design of the study

\section{Antioxidant activity}

DPPH Experiments were carried out according to the method of Blois with a slight modification (Fernandes et al. 2013). Briefly, a $0.1 \mathrm{mM}$ solution of DPPH radical solution in $\mathrm{MeOH} / \mathrm{H}_{2} \mathrm{O}(8: 2)$ was prepared. Then $1 \mathrm{~mL}$ of this solution was mixed with sample solution ( $3 \mathrm{~mL})(1 \mathrm{mg} / \mathrm{mL}$ final conc.). Finally, after $30 \mathrm{~min}$, the absorbance was measured at $517 \mathrm{~nm}$ by UV-spectrophotometer (U-3000 ${ }^{\circledR}$, Hitachi, Japan). BHT (butylated hydroxyl toluene) was used as positive control. The DPPH radical scavenging activity was calculated using the following relation.

DPPH radical scavenging activity $(\%)=$

$\frac{\text { Absorbance of blank - Absorbance of sample }}{\text { Absorbance of blank }} \times 100$

\section{Total Phenolic Compound Content}

Total phenolic compound content in the extract was determined spectrophotometrically by Folin-Ciocalteu method (Singleton and Rossi 1965). Dried extracts were resuspended in distilled water $(1 \mathrm{mg} / \mathrm{mL})$. Thirty microliters of each extract or distilled water (blank) was mixed with $3 \mathrm{~mL}$ distilled water in a test tube. Subsequently, $0.1 \mathrm{~mL}$ 
Folin-Ciocalteu phenol reagent was added to each test tube. The mixture was allowed to stand for $5 \mathrm{~min}$. Afterwards, $0.3 \mathrm{~mL} 20 \%$ sodium carbonate solution was added to the mixture, which was then allowed to stand for $30 \mathrm{~min}$ at $25^{\circ} \mathrm{C}$. The absorbance was determined at $765 \mathrm{~nm}$ with a UV-spectrophotometer (U-3000 ${ }^{\circledR}$, Hitachi, Japan). Gallic acid solution was used for calibration. Total phenolic compound content in aqueous and ethanol extract was expressed as gallic acid equivalents (GAEs).

\section{Determination of Phenolic Compounds by HPLC}

The phenolic compounds vanillic acid, ferulic acid, and vanillin were determined using high-performance liquid chromatography (HPLC) (Jin et al. 2005). The filtered samples were loaded into an HPLC system (Gilson, France) equipped with a $5 \mu \mathrm{m}$ TSK gel ODS-80Ts column (4.6 mm $\times 25 \mathrm{~cm}$; Tosoh, Tokyo, Japan) and an ultraviolet light detector operating at $280 \mathrm{~nm}$ using the solvents water:glacial acetic acid 95:5 (v/v) (solvent A) and methanol (solvent B) as the mobile phases with a flow rate of $0.6 \mathrm{~mL} / \mathrm{min}$. The elution sequence was as follows: 0 to $10 \mathrm{~min}, 90 \% \mathrm{~A}$ and $10 \% \mathrm{~B}$. The retention time was calculated by comparing HPLC results of samples with that of standard solutions (vanillic acid, ferulic acid, and vanillin).

\section{Antihistamine activity}

The skin-prick test was carried out by a dermatologist according to an approved protocol (Humphreys and Hunter 1991). The procedure was explained to healthy volunteering participants. Prior to the test, informed consent was obtained from participants according to the ethical guidelines of Gyeongsang National University. The participants were symptom-free and were not taking medications. Ten male (aged 25 to 28 years) and ten female (aged 21 to 29 years) undergraduate students were given an opportunity to volunteer for the experiment. All 20 people who agreed to participate considered themselves in good health. The ventral forearm of the participants was cleaned prior to exposure to test compounds. Then $1 \mathrm{~mL}$ of test compound that contained $3 \mathrm{~g}$ of aqueous extract and 25 to $95 \%$ ethanol extract dissolved in $100 \mathrm{~mL}$ of distilled water was applied on a $3 \times 3 \mathrm{~cm}$ for circle shape three times. Physiological sodium chloride solution was used as a negative control. An allergy lancet (J.N. Eberle GmBH, Schwabmuenchen, Germany) was used to prick the skin, and a drop of histamine solution (Histamine $0.1 \%$ W1130P 6370-001-043) or negative control were applied to extract areas on the skin. After 15 min, the average diameter of the resulting wheal and erythema was calculated by measuring the longest diameter and its perpendicular with calipers.

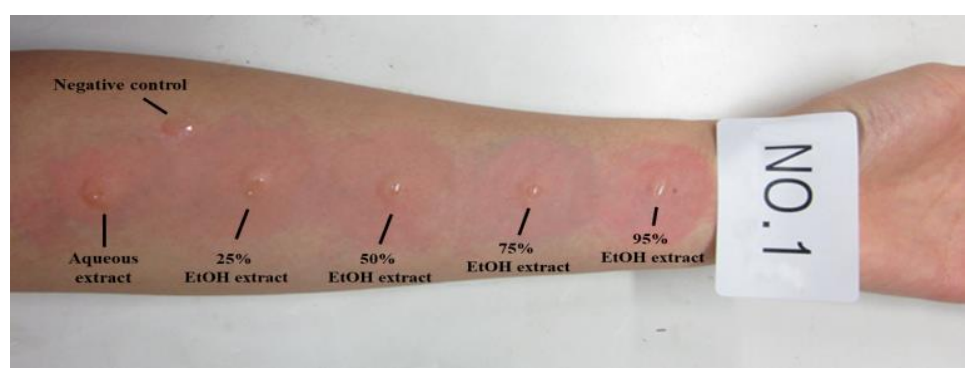

Fig. 2. Skin prick tests of aqueous extract and ethanolic (25\% EtOH, $50 \% \mathrm{EtOH}, 75 \% \mathrm{EtOH}$, and $95 \% \mathrm{EtOH}$ ) extract of steam-exploded oak. Negative control: physiological sodium chloride solution 


\section{Emollient Containing Steam-exploded Oak Extract on Atopic Dermatitis Patients}

Patients of the White-Line Skin Clinic, Changwon, Gyeongnam, Korea, who were diagnosed with atopic dermatitis according to the criteria of the Korean Dermatological Association (Park et al. 2006), and had agreed to participate in the clinical study and signed informed consent were included. Eighteen patients aged 5 to 16 years were included. Eight out of 21 patients had a family history of atopic dermatitis, and three had a personal history of allergic rhinitis or bronchial asthma. Patients were treated medically and asked to apply either emollient control or emollient which contained 5\% concentration of 50\% EtOH extract of steam-exploded oak to symmetric lesion areas on the skin for 10 weeks. The effects were graded subjectively by patients on a scale of 0 to 5 , where $0=$ no effects or aggravation, $1=$ less than $20 \%$ improvement, $2=21$ to $40 \%$ improvement, $3=41$ to $60 \%$ improvement, $4=61$ to $80 \%$, and $5=$ more than $80 \%$ improvement.

\section{Statistical analysis}

Data were expressed as mean \pm standard deviation (SD) of triplicates. Statistical analyses were performed by the Student's t-test using the SPSS software v.21 (IBM Corporation). Values with $\mathrm{p}<0.05$ or $\mathrm{p}<0.001$ were considered statistically significant. In the data presentation, $p<0.05$ was indicated by '*', whereas $p<0.001$ was indicated by '**'.

\section{RESULTS and DISCUSSION}

Oak extract has long been used as an additive in food, oral and topical medicines, and cosmetics. Therefore, topical formulations of this extract would likely be safe for longterm treatment, without side effects. Furthermore, it is economically efficient to extract antioxidants from large trees, such as oaks. In Korea, many parents find it difficult and inconvenient to administer prescribed oral medicines to their children. Therefore, steamexploded oak extract as a novel topical agent would provide them with alternative options and facilitate better treatment for patients.

\section{Effect of Steam Explosion Condition on the Antioxidant Activity of Oak Extract}

In this study, to increase the antioxidant activity of oak ( $Q$. variabilis), a steam explosion treatment was applied. Figure 3 summarizes the effects of steam-explosion on DPPH radical scavenging activity of oak. The DPPH radical scavenging activity increased with the increasing residence time of steam explosion. Oak that had been steam-exploded for 20 and 30 min exhibited similar strong DPPH radical scavenging activity as BHT. Oak subjected to steam explosion at $25 \mathrm{~kg} / \mathrm{cm}^{2}$ pressure for 20 min showed the highest percentage of DPPH radical scavenging activity $(77.9 \%)$ compared with all other extracts and was therefore selected for use in the subsequent experiments. Gong et al. (2012) reported that steam-explosion pretreatment has been applied to increase the extraction yield and antioxidant activity of phenolic and other bioactive compounds. The increase in antioxidant activity with increased residence time of steam-explosion as reported previously (Gong et al. 2012) was supported by the present study. The decrease of the DPPH radical scavenging activity a steam temperature of $250^{\circ} \mathrm{C}$ and at residence time 30 min seems to be due to further degradation of separated phenolic compounds and nonaromatic compounds that decreased the radical scavenging activity (Kurosumi et al. 2007). 


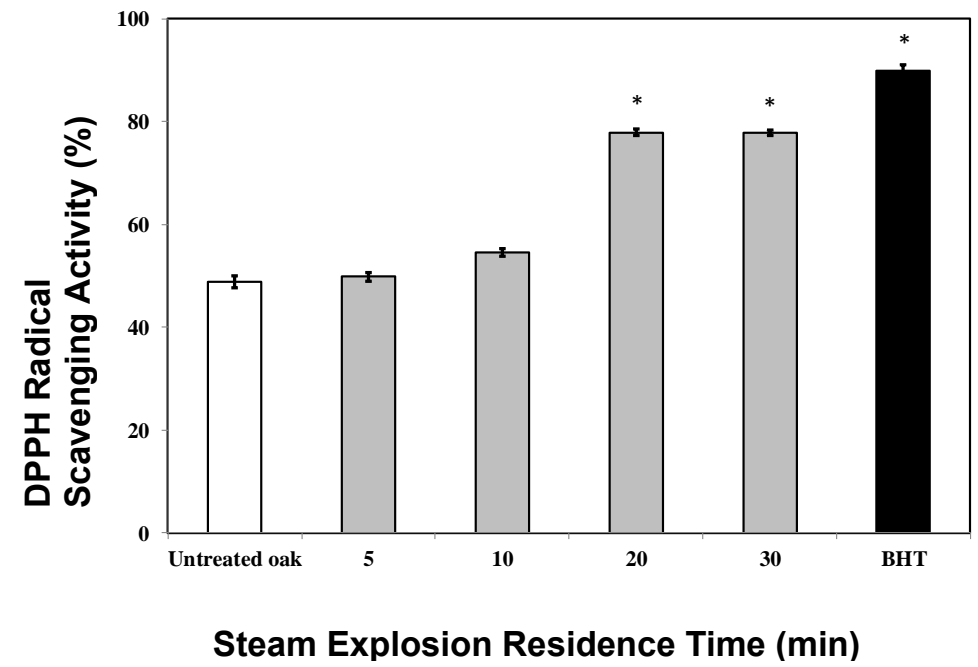

Fig. 3. Effect of steam-explosion residence time on the antioxidant activity of oak extract using the DPPH assay. Values are expressed as the mean \pm SD of three independent experiments $\left({ }^{*} P<0.05\right.$, vs. untreated oak). DPPH, 2,2-diphenyl-1-picrylhydrazyl radical; positive control; BHT (butylated hydroxyl toluene).

\section{Effect of Extraction Solvent on Extract Yield}

The yields of steam-exploded oak extracted with water and ethanol are shown in Fig. 4. As shown, the extraction yield was greatly influenced by the concentration of ethanol. Steam-exploded oak extracted with water, $25 \%, 50 \%, 75 \%$, and $95 \%$ EtOH yielded 17.2, 20.9, 28.8, 24.6, and 15.3\% extracts, respectively. The extract yield increased with the increase of ethanol concentration until reaching a maximum $(28.8 \%)$ at $50 \%$, after which extract yield decreased. The reason might be related to the polarity of ethanol and solubility of phenolic compounds in steam-exploded oak (Sun et al. 2011).

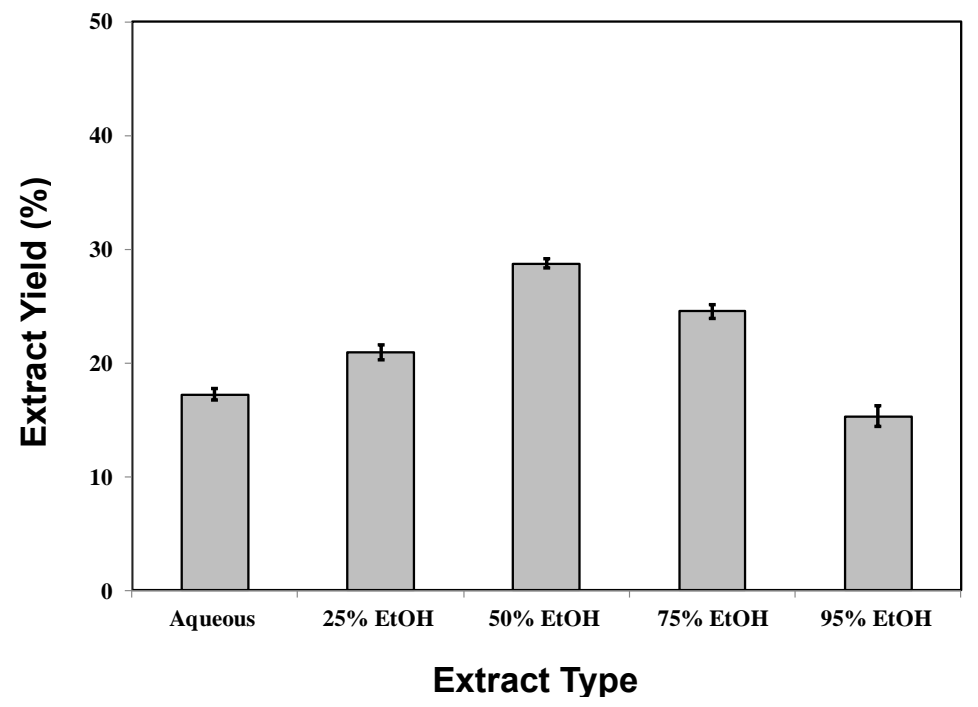

Fig. 4. Extract yield of aqueous extract and ethanolic extracts $(25 \% \mathrm{EtOH}, 50 \% \mathrm{EtOH}, 75 \% \mathrm{EtOH}$, and $95 \% \mathrm{EtOH}$ ) of steam-exploded oak 


\section{Effects of Extract Type on Total Phenolic Compound Content}

Figure 5 shows the total phenolic compound content of aqueous, 25\%, 50\%, 75\%, and $95 \%$ EtOH extracts of steam-exploded oak. The total phenolic compound content values, determined using the Folin-Ciocalteu method, are expressed as gallic acid equivalents (mg GAE/g extract). The total phenolic compound content of all extracts can be listed in the following descending order: $50 \% \mathrm{EtOH}$ extract $>25 \% \mathrm{EtOH}$ extract $>95 \%$ $\mathrm{EtOH}$ extract $>75 \% \mathrm{EtOH}$ extract $>$ aqueous extract. The $50 \% \mathrm{EtOH}$ steam-exploded oak extract of contained the highest total phenolic compoound content. Kim et al. (2005) reported a polyphenol content of $32.5 \mathrm{mg}$ in Quercus extract, and Shimada and Saitoh (2006) reported a phenolic compound of 3.2\%. Compared to that of these earlier reports, the yield of phenolic compounds in the current study was higher, possibly due to steamexplosion and other extraction conditions used.

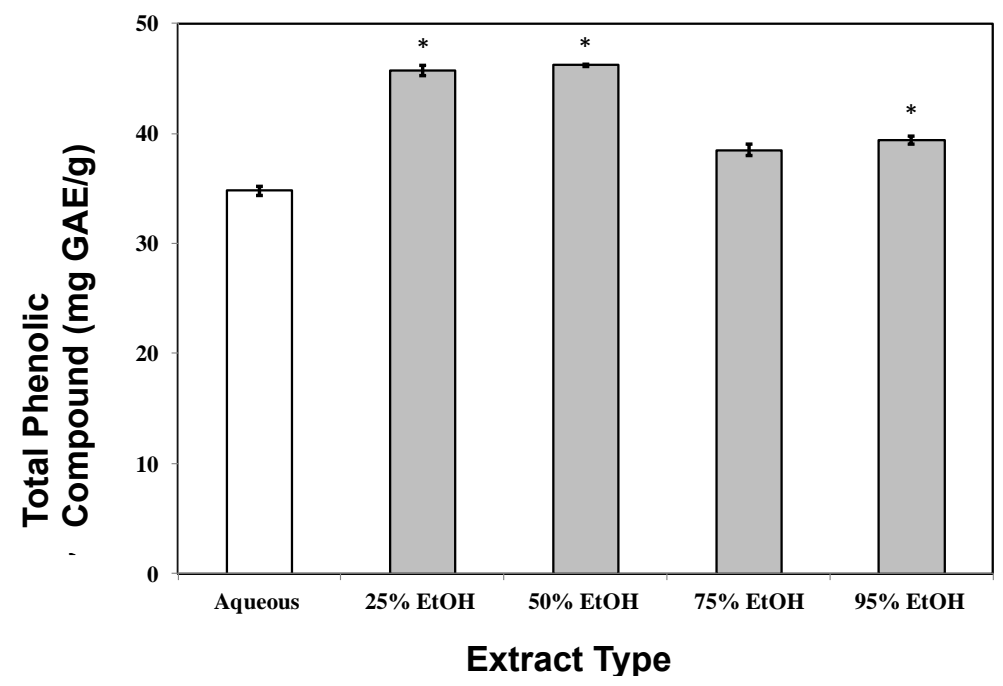

Fig. 5. Effect of extract type on the total phenolic compound content of aqueous and ethanolic extracts $(25 \% \mathrm{EtOH}, 50 \% \mathrm{EtOH}, 75 \% \mathrm{EtOH}$, and $95 \% \mathrm{EtOH})$ of steam-exploded oak using the Folin-Ciocalteu assay. Values are expressed as the mean \pm SD of three independent experiments ( ${ }^{*} \mathrm{P}<0.05$, vs. aqueous extract). Total phenolic compound content is expressed as mg gallic acid equivalent/g extract.

\section{Effects of Extract Type on Phenolic Compounds}

The phenolic compounds vanillic acid, ferulic acid, and vanillin in the extracts were determined using HPLC analysis. The vanillic acid, ferulic acid, and vanillin contents of the extracts ranged from $3.2 \%$ to $17.3 \%, 1.1 \%$ to $2.8 \%$, and $0.7 \%$ to $1.4 \%$ of the dry extract (Fig. 6), respectively. The $50 \% \mathrm{EtOH}$ extract had the highest vanillic acid and vanillin concentrations, which were significantly higher than those of the aqueous extract $(p<0.001)$. Increases of the vanillic acid and ferulic acid suggested that some of the ester bonds of the lignin were cleaved and so was the guaiacin as well (Chen and Liu 2007). Koyama et al. (2006) reported that a phenolic compound-containing Taxus yunnanensis extract exhibited anti-allergic and anti-atopic dermatitis activities, which result was supported by the results in the present study, suggesting that vanillin acid has antiallergenic properties. 


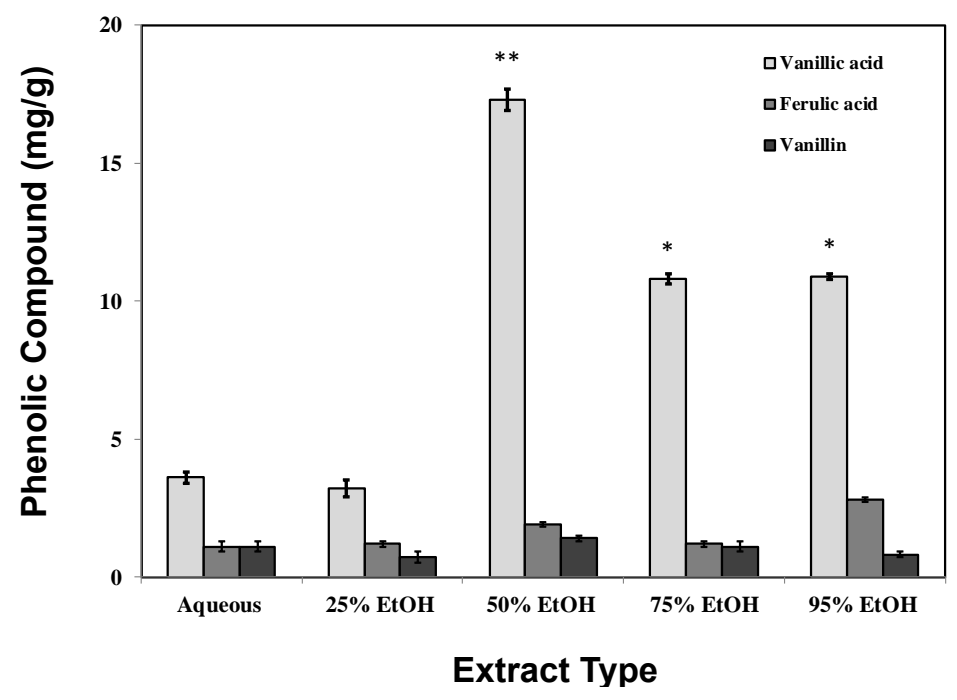

Fig. 6. Effect of extract type on the phenolic compound of aqueous and ethanolic extracts $(25 \%$ $\mathrm{EtOH}, 50 \% \mathrm{EtOH}, 75 \% \mathrm{EtOH}$, and $95 \% \mathrm{EtOH}$ ) steam-exploded oak evaluated by HPLC analysis. Values are expressed as the mean $\pm S D$ of three independent experiments $\left({ }^{*} P<0.05,{ }^{* *} P<0.001\right.$, $v s$. aqueous extract).

\section{Effects of Extract Type on the Antioxidant Activity of Steam-exploded Oak}

As the inflammatory symptoms of atopic dermatitis progress, the production of superoxide anion $\left(\mathrm{O}_{2}-\right)$ and related reactive oxygen species (ROS), including $\mathrm{H}_{2} \mathrm{O}_{2}$ and $\mathrm{OH}^{-}$(Trenam et al. 1992; Li et al. 2015), increases and further exacerbates the inflammation. Therefore, patients with atopic dermatitis require antioxidant therapy to maintain oxidative stress homeostasis. Accordingly, the antioxidant activity of the steamexploded oak extract was investigated using a DPPH radical scavenging assay.

Figure 7 lists the antioxidant activity (DPPH radical scavenging activity) of water aqueous, $25 \%, 50 \%, 75 \%$, and $95 \%$ EtOH extracts of steam-exploded oak. Among all extracts, the $50 \%$ EtOH extract exhibited the highest DPPH radical scavenging activity $(82.2 \%)$, despite being not significantly different than that of BHT $(85.4 \%)$. The DPPH radical scavenging activities of all extracts are listed in the following descending order: $50 \%$ EtOH extract $>75 \%$ EtOH extract $>25 \%$ EtOH extract $>95 \%$ EtOH extract $>$ aqueous extract. The $50 \% \mathrm{EtOH}$ steam-exploded oak extract elicited the highest antioxidant activity. Interestingly, the steam-exploded oak extract exhibited a similar DPPH radical scavenging activity level to that of BHT (positive control) and previous studies (Castro et al. 2008; Garrote et al. 2014). Furthermore, the present results indicated that steam-exploded oak extract is a powerful free radical scavenger with high potential for the treatment of atopic dermatitis. 


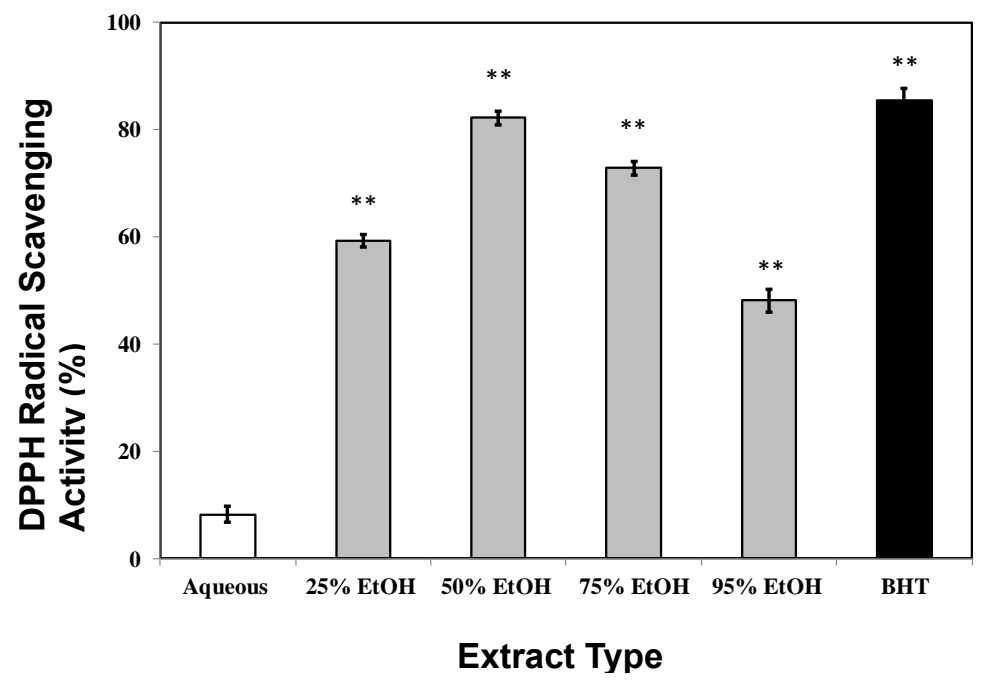

Fig. 7. Effect of extract type on the antioxidant activity of aqueous and ethanolic extracts $(25 \%$ $\mathrm{EtOH}, 50 \% \mathrm{EtOH}, 75 \% \mathrm{EtOH}$, and $95 \% \mathrm{EtOH}$ ) of steam-exploded oak determined by DPPH assay. Values are expressed as the mean \pm SD of three independent experiments $\left({ }^{* *} P<0.001\right.$, vs. aqueous extract). DPPH: 2,2-diphenyl-1-picrylhydrazyl radical; positive control; BHT (butylated hydroxyl toluene).

\section{Effects of Extract Type on Antihistamine Activity of Steam-exploded Oak Extract}

Figure 8 shows the antihistamine activity of aqueous, $25 \%, 50 \%, 75 \%$, and $95 \%$ EtOH extracts of steam-exploded oak in the skin prick test. Treatment with $50 \% \mathrm{EtOH}$ steam-exploded oak extract significantly decreased the wheal and erythema response, with respective diameters of $4.9 \mathrm{~mm}$ and $22 \mathrm{~mm}$, which were significantly smaller than those of the negative control ( $7.4 \mathrm{~mm}$ and $31.4 \mathrm{~mm}$, respectively) $(\mathrm{p}<0.002)$. In the present study, it was found that the application ointment containing steam-exploded oak extract prevented histamine-induced wheals and erythema in atopic dermatitis patients.

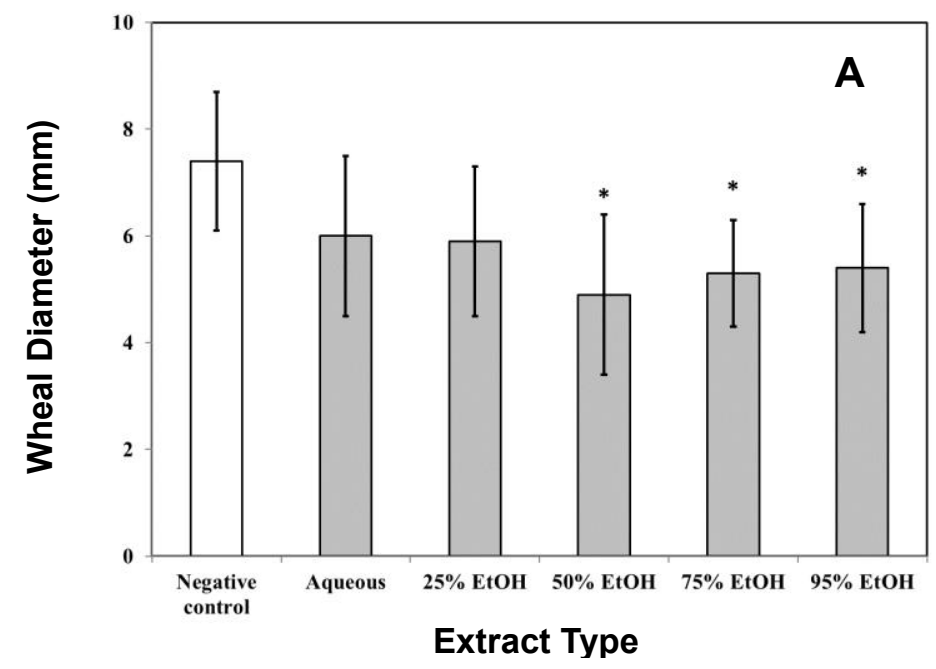




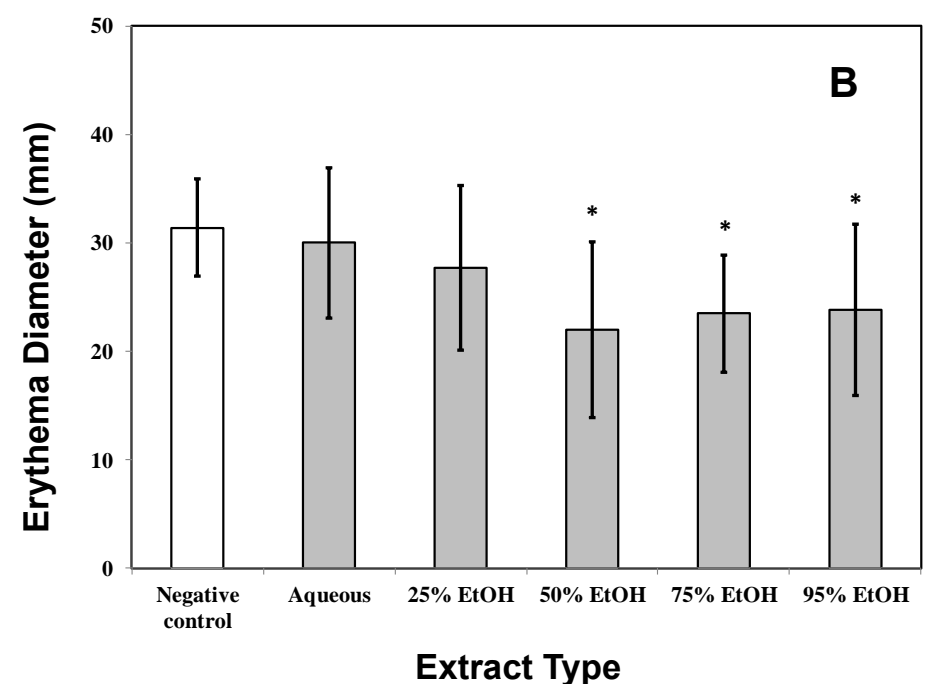

Fig. 8. Effect of extract type on the antihistamine activity of aqueous and EtOH extracts $(25 \% \mathrm{EtOH}$, $50 \% \mathrm{EtOH}, 75 \% \mathrm{EtOH}$, and $95 \% \mathrm{EtOH}$ ) of steam-exploded oak determined by skin prick test. (A) Wheal diameter (B) Erythema diameter. Participants: Ten male (aged 25 to 28 years) and ten female (aged 21 to 29 years); histamine-induced skin: Histamine 0.1\% W1130P 6370-001-043); Negative control: Physiological sodium chloride solution. Values are expressed as the mean \pm SD of three independent experiments $\left({ }^{*} P<0.05\right.$, vs. negative control).

\section{Effect of Steam-exploded Oak Extract on Patients with Atopic Dermatitis}

As the $50 \%$ EtOH extract of steam-exploded oak exhibited the highest antihistamine activity, it was applied in a clinical test on atopic dermatitis patients. Figure 9 shows the clinical efficacy of the steam-exploded oak extract against the symptoms of atopic dermatitis. Following treatment, patients treated with steam-exploded oak extract-based emollient reported significant improvements in sleep disturbances, pruritus, xerosis, skin scratching, and erythema relative to those experienced before treatment period $(p<0.002)$. The patients reported fewer sleep disturbances, itching, xerosis, skin scratching, and erythema following treatment with steam-exploded oak extract. This resulted indicating that this topical treatment ameliorated these histamine-induced symptoms. The addition of steam-exploded oak extract to commercial products or medications may be a safe and highly effective way to alleviate the symptoms of atopic dermatitis and prevent the vicious cycle of pruritus, scratching, sleep disturbance, and stress. 


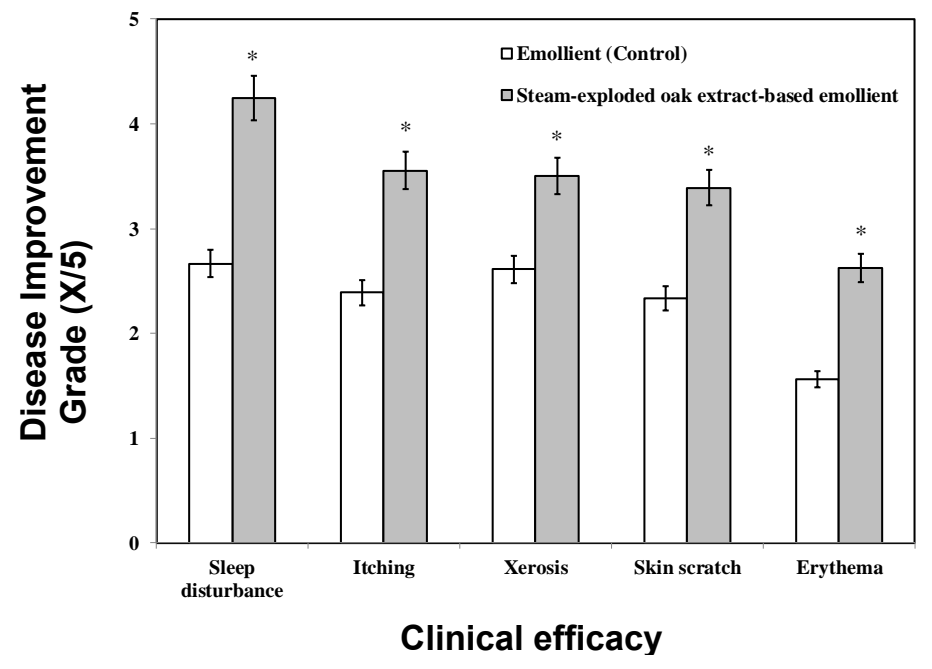

Fig. 9. Disease improvement grade of $50 \% \mathrm{EtOH}$ steam-exploded oak extract-based emollient. Atopic dermatitis patients: Eighteen (aged 5 to 16 years), Eight out of twenty-one patients had family history of atopic dermatitis, and 3 had personal history of allergic rhinitis or bronchial asthma; scale of 0 to 5 : $0=$ no effects or aggravation, $1=$ less than $20 \%$ improvement, $2=21$ to $40 \%$ improvement, $3=41$ to $60 \%$ improvement, $4=61$ to $80 \%$, and $5=$ more than $80 \%$ improvement.

\section{CONCLUSIONS}

1. The results showed that antioxidant activity of steam-exploded oak extracts increased with residence time ( 5 to $30 \mathrm{~min}$ ) of the steam explosion process and a $50 \%$ EtOH steamexploded (steam explosion condition: $25 \mathrm{~kg} / \mathrm{cm}^{2}$ pressure, $20 \mathrm{~min}$ ) oak extract yielded high total phenolic compound content and exhibited strong antioxidant activity.

2. Our results indicated that a $50 \%$ EtOH steam-exploded oak extract also decreased histamine-induced wheal and erythema. The antihistamine activity was highest in the $50 \%$ ethanol extract. An emollient containing this extract reduced sleep disturbances, itching, xerosis, skin scratching, and erythema in atopic dermatitis patients.

3. In conclusion, steam-exploded oak extract was therefore suggested as an effective and safe component of topical medication for the treatment of atopic dermatitis, thus avoiding inconveniences and possible complications after unnecessary and long-term use.

\section{ACKNOWLEDGMENTS}

This research was supported by Basic Science Research Program through the National Research Foundation of Korea (NRF) funded by the Ministry of Education (2018R1D1A1A02045243). 


\section{REFERENCES CITED}

Al-Waili, N. S. (2003). "Topical application of natural honey, beeswax and olive oil mixture for atopic dermatitis or psoriasis: partially controlled, single-blinded study," Complement. Ther. Med. 11, 226-234. DOI: 10.1016/s0965-2299(03)00120-1

Briganti, S., and Picardo, M. (2003). "Antioxidant activity, lipid peroxidation and skin diseases. What's new," J. Eur. Acad. Dermatol. Venereol. 17, 663-669. DOI:

10.1046/j.1468-3083.2003.00751.x

Castro, E., Conde, E., Moure, A., Falqué, E., Cara, C., Ruiz, E., and Domínguez. H. (2008). "Antioxidant activity of liquors from steam explosion of Olea europea wood. Wood Sci. Technol. 42(7), 579-592. DOI: 10.1007/s00226-007-0169-y

Choi, J. K., Oh, H. M., Lee, S. Y., Kwon, T. K., Shin, T. Y., Rho, M. C., and Kim, S. H. (2014). "Salvia plebeian suppresses atopic dermatitis-like skin lesions," Am. J. Chin. Med. 42, 967-985. DOI: 10.1142/s0192415x1450061x

Działo, M., Mierziak, J., Korzun, U., Preisner, M., Szopa, J., and Kulma, A. (2016). “The potential of plant phenolics in prevention and therapy of skin disorders," Int. J. Mol. Sci. 17(2), 160. DOI: 10.3390/ijms 17020160

Fernandes, F., Ramalhosa, E., Pires, P., Verdial, J., Valentão, P., Andrade, P., Bentoa, A., and Pereiraa, J. A. (2013). "Vitis vinifera leaves towards bioactivity," Ind. Crops Prod. 43, 434-440. DOI: 10.1016/j.indcrop.2012.07.031

Garrote, G., Cruz, J. M., Moure, A., Domínguez, H., and Parajó, J. C. (2004). "Antioxidant activity of byproducts from the hydrolytic processing of selected lignocellulosic materials," Trends Food Sci. Technol. 15(3-4), 191-200. DOI: 10.1016/j.tifs.2003.09.016

Gong, L., Huang, L., and Zhang, Y. (2012). "Effect of steam explosion treatment on Barley bran phenolic compounds and antioxidant capacity," J. Agric. Food Chem. 60(29), 7177-7184. DOI: 10.1021/jf301599a

Hon, K. L., Leung, T. F., Wong, Y., Lam, W. K., Guan, D. Q., Ma, K. C., Sung, Y. T., Fok, T. F., and Leung, P. C. (2004). "A pentaherbs capsule as a treatment option for atopic dermatitis in children: an open-labeled case series," Am. J. Chin. Med. 32, 941-950. DOI: $10.1142 / \mathrm{s} 0192415 \times 04002545$

Chen, H., and Liu, L. (2007). "Unpolluted fractionation of wheat straw by steam explosion and ethanol extraction," Bioresour. Technol. 98(3), 666-676. DOI: 10.1016/j.biortech.2006.02.029

Humphreys, F., and Hunter, J. A. (1991). "The effects of astemizole, cetirizine and loratadine on the time course of weal and flare reactions to histamine, codeine and antigen," Br. J. Dermatol. 125(4), 364-367. DOI: 10.1111/j.13652133.1991.tb14173.x

Jin, U. H., Lee, J. Y., Kang, S. K., Kim, J. K., Park, W. H., and Kim, J. G. (2005). “A phenolic compound, 5-caffeoylquinic acid (chlorogenic acid), is a new type and strong matrix metalloproteinase-9 inhibitor: Isolation and identification from methanol extract of Euonymus alatus," Life Sci. 77(22), 2760-2769. DOI: 10.1016/j.1fs.2005.02.028

Jung, J. Y., Lim, K. B., Kim, J. S., Park, H. M., and Yang, J. K. (2015). "Utilization of wood by-product and development of horticultural growing media," Korean J. Hortic. Sci. Technol. 33(3), 435-442. DOI: 10.7235/hort.2015.14161

Kim, S. J., Youn, K. S., and Park, H. S. (2005). "Antioxidative effect of pine, oak, and 
lily pollen extracts," Korean J. Food Sci. Technol. 37(5), 833-837.

Kirby, A. J., and Schmidt, R. J. (1997). "The antioxidant activity of Chinese herbs for eczema and of placebo herbs-I," J. Ethnopharmacol. 56, 103-108. DOI: 10.1016/s0378-8741(97)01510-9

Kojima, T., Akiyama, H., Sasai, M., Taniuchi, S., Goda, Y., Toyoda, M., and Kobayashi, Y. (2000). "Anti-allergic effect of apple polyphenol on patients with atopic dermatitis: A pilot study," Allergol. Int. 49, 69-73. DOI: 10.1046/j.14401592.2000.00161.x

Koyama, J., Morita, I., Kobayashi, N., Hirai, K., Simamura, E., Nobukawa, T., and Kadota, S. (2006). "Antiallergic activity of aqueous extracts and constituents of Taxus yunnanensis,” Biol. Pharm. Bull. 29(11), 2310-2312. DOI: 10.1248/bpb.29.2310

Kurosumi, A., Sasaki, C., Kumada, K., Kobayashi, F., Mtui, G., and Nakamura. Y. (2007). "Novel extraction method of antioxidant compounds from Sasa palmata (Bean) Nakai using steam explosion," Process Biochem. 42(10), 1449-1453. DOI: 10.1016/j.procbio.2007.06.007

Lee, H. Y., Ha, H. K., Lee, J. K., Park, S. J., Jeong, S. I., and Shin, H. K. (2014). “The Leaves of Broussonetia kazinoki Siebold inhibit atopic dermatitis-like response on mite allergen-treated Nc/Nga mice," Biomol. Ther. 22(5), 438-444. DOI:

10.4062/biomolther.2014.023

Lee, C. S., Yi, E. H., Kim, H. R., Huh, S. R., Sung, S. H., Chung, M. H., and Ye, S. K. (2011). "Anti-dermatitis effects of oak wood vinegar on the DNCB-induced contact hypersensitivity via STAT3 suppression,” J. Ethnopharmacol. 135, 747-753. DOI: 10.1016/j.jep.2011.04.009

Li, M. H., Wo, H. C., Yao, H. J., Lin, C. C., Wen, S. F., and Pan, I. H. (2015). “Antrodia cinnamonea extract inhibits Th17 cell differentiation and ameliorates imiquimodinduced psoriasiform skin inflammation," Am. J. Chin. Med. 43(7), 1407-1417. DOI: $10.1142 / \mathrm{s} 0192415 \times 15500792$

Moriyama, M. T., Miyazawa, K., Noda, K., Oka, M., Tanaka, M., and Suzuki, K. (2007). "Reduction in oxalate-induced renal tubular epithelial cell injury by an extract from Quercus salicina Blume/Quercus stenophylla Makino," Urol. Res. 35, 295-300. DOI: 10.1007/s00240-007-0114-4

Muliawan, S. Y., Kit, L. S., Devi, S., Hashim, O., and Yusof, R. (2006). "Inhibitory potential of Quercus lusitanica extraction dengue virus type 2 replication," Southeast Asian J. Trop. Med. Public Health 37,132-135. DOI:10.1016/s0378-8741(01)00395-6

Nur Syukriah, A. R., Lisa, M. S., Harisun, Y., and Fadzillah, A. A. M. (2014). "Effect of solvent extraction on antioxidant and antibacterial activities from Quercus infectoria (Manjakani)," Int. Food Res. J. 21, 1031-1037. DOI: 10.1016/j.bcab.2019.101104

Park, Y. L., Kim, H. D., Kim, K. H., Kim, M. N., Kim, J. W., and Ro, Y. S. (2006). "Report from ADRG: A study on the diagnostic criteria of Korean atopic dermatitis," Korean J. Dermatol. 44, 659-663.

Reuter, J., Wölfle, U., Weckesser, S., and Schempp, C. (2010). "Which plant for which skin disease? Part 1: Atopic dermatitis, psoriasis, acne, condyloma and herpes simplex," J. Dtsch. Dermatol. Ges. 8, 788-796. DOI: 10.1111/j.16100387.2010.07496.x

Shimada, T., and Saitoh, T. (2006). "Re-evaluation of the relationship between rodent populations and acorn masting: a review from the aspect of nutrients and defensive chemicals in acorns," Popul. Ecol. 48(4), 341-352. DOI: 10.1007/s10144-006-0012-6 
Singleton, V. L., and Rossi, J. A. (1965). "Colorimetry of total phenolics with phosphomolybdic-phosphotungstic acid reagents," Am. J. Enol. Vitic. 16,144-158.

Sun, S. L., Wen, J. L., Ma, M. G., Sun, R. C., and Jones, G. L. (2014). "Structural features and antioxidant activities of degraded lignins from steam exploded bamboo stem," Ind. Crops Prod. 56:128-136. DOI: 10.1016/j.indcrop.2014.02.031

Sun, Y., Xu, W., Zhang, W., Hu, Q., and Zeng, X. (2011). "Optimizing the extraction of phenolic antioxidants from kudingcha made from Ilex kudingcha C.J. Tseng by using response surface methodology," Sep. Purif. Technol. 78(3), 311-320. DOI: 10.1016/j.seppur.2011.01.038

Taofiq, O., González-Paramása, A. M., Martinsa, A., Barreiroc, M. F., and Ferreiraa, I. C. F. R. (2016). "Mushrooms extracts and compounds in cosmetics, cosmeceuticals and nutricosmetics - A review," Ind. Crop. Prod. 90, 38-48. DOI: 10.1016/j.indcrop.2016.06.012

Trenam, C. W., Blake, D. R., and Morris, C. J. (1992). "Skin inflammation: Reactive oxygen species and the role of iron," J. Invest. Dermatol. 99(6), 675-682. DOI: 10.1111/1523-1747.ep12613740

Tsang, M. S. M., Jiao, D., Chan, B. C. L., Hon, K. L., Leung, P. C., Lau, C. B. S., Wong, E. C. W., Cheng, L., Chan, C. K. M., Lam, C. W. K., and Wong, C. K. (2016). "Antiinflammatory activities of pentaherbs formula, berberinem gallic acid and chlorogenic acid in atopic dermatitis-like skin inflammation," Molecules 21(4), 519. DOI: 10.3390/molecules 21040519

Wang, X., Jia, W., Zhao, A., and Wang, X. (2006). “Anti-influenza agents from plans and traditional Chinese medicine," Phytother. Res. 20, 335-341. DOI: 10.1002/ptr.1892

Article submitted: January 7, 2019; Peer review completed: April 25, 2019; Revisions accepted: October 6, 2020; Published: October 7, 2020.

DOI: $10.15376 /$ biores.15.4.8770-8783 